\title{
大洋型超高压变质带的地质特征及其研究意义: 以西南天山、柴北缘超高压变质带为例
}

\author{
张立飞, 吕增, 张贵宾, 宋述光
}

造山带与地壳演化教育部重点实验室, 北京大学地球与空间科学学院, 北京 100871

E-mail: lfzhang@pku.edu.cn

2008-04-21 收稿, 2008-07-24 接受

国家自然科学基金(批准号: 40730314)资助项目

\begin{abstract}
摘要 在总结洋壳深俯冲超高压变质带的基本地质特征的基础上, 较深入地论述了洋壳 深俯冲超高压变质作用研究意义和存在的问题. 大洋型超高压变质带的基本特征是以典 型的洋壳组合的原岩建造为特征, 其变质作用峰期温度较低属于低温榴辉岩相范围, 在 递进和退变过程中出现蓝片岩相变质过程, 具有低的、冷俯冲带的地热梯度, 并且在岩 石组合方面常常与蛇绿岩带伴生. 大洋型超高压变质带的深入研究对于建立冷俯冲带变 质反应系列, 探讨俯冲带的水流体是如何被带到地幔深处以及建立冷俯冲带超高压变质 作用类型都具有重要意义. 深俯冲超高压变质洋壳岩石抬升、折返机制的研究是目前超 高压变质作用研究最具挑战性的问题之一, 其深入研究对于探讨超高压变质作用发生机 理、建立更加广泛的超高压变质岩石抬升、折返机制具有重要意义; 洋壳深俯冲超高压 变质岩作为俯冲到地幔深度又折返到地表的岩石, 见证了俯冲与折返的全过程, 是研究 俯冲变质带中元素地球化学行为及其物质循环的最理想场所之一; 洋壳俯冲到陆壳俯冲 一碰撞是俯冲碰撞造山带形成演化的基本方式, 也是目前板块构造理论研究的前沿领域. 同时, 对中国西部西南天山和柴北缘 2 个具有洋壳深俯冲特征的超高压变质带研究现状 和存在的问题也展开了讨论.
\end{abstract}

关键词

大洋型超高压变质

冷俯冲带

西南天山

柴北缘
20 世纪七、八十年代的有关蓝片岩以及相关的 低温榴辉岩的研究, 总结出了太平洋型和阿尔卑斯 型两种俯冲带类型 $[1,2]$, 通常也简单地称之为大洋型 和大陆型 2 种类型的俯冲带 ${ }^{[3]}$. 阿尔卑斯型俯冲带变 质作用的进一步研究引发了大陆深俯冲超高压变质 作用 ${ }^{[4]}$; 同时研究认为太平洋型的大洋型俯冲带不可 能出现超高压变质矿物. 直到 20 世纪 90 年代初在西 Alps的Zermatt-saas带典型的洋壳岩石中第一次发现 了柯石英 ${ }^{[5]}$, 人们才认识到大洋型俯冲带变质作用也 可以达到地幔深度, 并发生超高压变质后折返到地 表. 近年来我们又在西南天山典型的大洋型俯冲带 中发现了一系列超高压变质矿物 ${ }^{[6] 9]}$, 表明大洋型超 高压变质带是一种新类型的超高压变质带. 本文以
中国西部西南天山和柴北缘超高压变质带为例, 较 深入地介绍了大洋型超高压变质带的基本地质特征 和存在的问题及其进一步研究的地质意义.

\section{1 大洋型超高压变质带的基本特征}

通过详细的比较目前报道的典型洋壳岩石深俯 冲超高压变质带, 它们在原岩建造、变质作用和岩石 组合等方面都具有其独特的地质特征.

\section{1 原岩建造特征}

具有典型的洋壳岩石组合特征, 从底部的超基性 岩、变质玄武岩到变质沉积岩都能完整地保留下来. 如 西阿尔卑斯的 Zermatt-saas 超高压变质带保存完整的洋 壳的“三位一体”组成, 如出现在枕状构造玄武岩和 

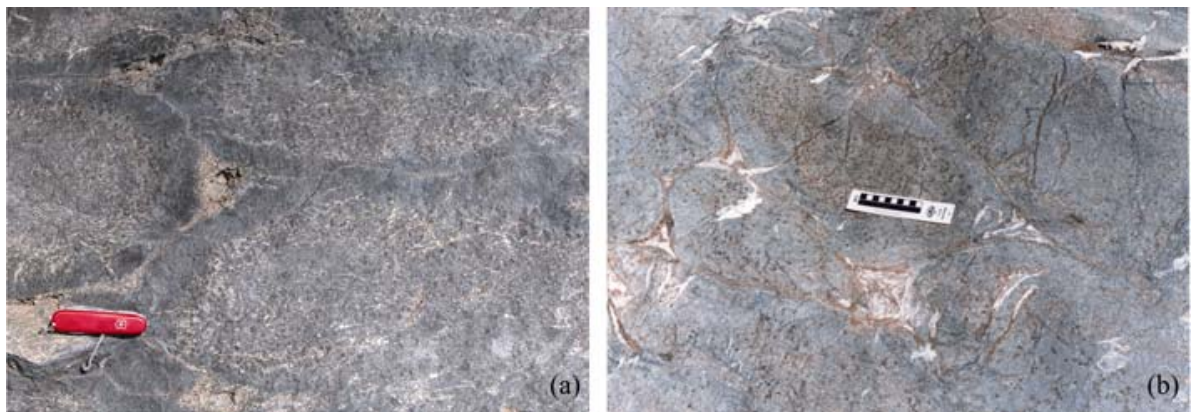

图 1 洋壳俯冲榴辉岩相变质的枕状玄武岩

(a) 西阿尔卑斯Zermatt-Saas带榴辉岩相变质的枕状玄武岩 ${ }^{[17]}$; (b) 新疆西南天山榴辉岩相变质的枕状玄武岩 ${ }^{[18]}$

变质为榴辉岩的层状辉长岩底部的变质超基性岩经 历了超高压变质过程, 其峰期的变质温压条件达到

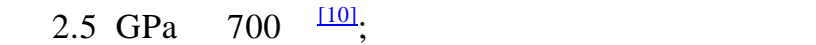
中的部分超基性岩(蛇纹岩)中发现了经历强烈异剥 钙榴岩化的榴辉岩，虽然目前还没有确切的标志性 矿物来证明这些蛇纹岩经历了超高压变质，但至少 说明这些蛇纹岩曾经历了榴辉岩相的变质作用过程 [11,12]; 柴北缘超高压变质带中也零星地发育有蛇纹 岩化的超基性岩体，如沙柳河蛇纹岩与由层状辉长 岩变质形成的蓝晶石榴辉岩伴生, 在这些蛇纹岩中 发现的由蛇纹石进一步变质形成的富 $\mathrm{Mg}(\mathrm{Fo}=94 \%)$ 橄榄石表明经历了与板块俯冲榴辉岩相变质有关的 转化过程 $[13]$. 其变质的层状辉长岩 (榴辉岩)在西 Alps ${ }^{[14]}$ 和柴北缘 ${ }^{[13,15]}$ 都有发育，但在西天山超高压 变质带中至今没有发现类似的变质辉长岩体 ${ }^{[16]}$. 典 型洋壳组合中部多为由玄武岩变质形成的榴辉岩, 这在这 3 个超高压变质带中都有报道, 并且有保存完 好的具有玄武岩的枕状构造, 如西Alps的Zermattsaas带中的榴辉岩和西南天山榴辉岩都已发现保持 完好的由枕状玄武岩变质形成的榴辉岩(图 1), 这也 是目前为止世界范围内 2 个最典型的保存有枕状构 造的由玄武岩变质形成的榴辉岩 ${ }^{[17]}$. 地球化学研究 显示它们具有典型的大洋玄武岩地球化学特征, 如 西南天山榴辉岩-蓝片岩和柴北缘榴辉岩等, 同时具 有NMORB, EMORB和OIB特征 ${ }^{[13,19,20]}$ ，并且具有典 型的亏损地幔 $\left(\varepsilon_{\mathrm{Nd}}(t)>0\right)$ 的特征，与典型的大别-苏鲁 榴辉岩石具有明显的不同(图 2). 典型洋壳组合上部 发育的变质沉积岩和碳酸岩石都比较普遍, 并在其 中部分变质沉积岩中发现了超高压变质矿物. 如在 Zermatt-sass带最早发现的柯石英包体就是在变质的
沉积岩石(石榴石多硅白云母石英片岩)中 ${ }^{[5]}$, 在西南 天山超高压变质带中的变质泥质岩中发现了变质菱 镁矿和方解石转变为白云石的分解反应等 ${ }^{[8]}$. 最近研 究人员又在石榴子石-绿辉石-白云母片岩中发现了 保存完整的柯石英包体 ${ }^{[23]}$. 总之, 洋壳深俯冲超高压 变质带的原岩组合相对保存的都比较完整, 变质程 度没有明显区别, 表明洋壳深俯冲超高压变质过程 属于整体俯冲和抬升过程, 与大陆深俯冲出现的拆 离解耦过程截然不同.

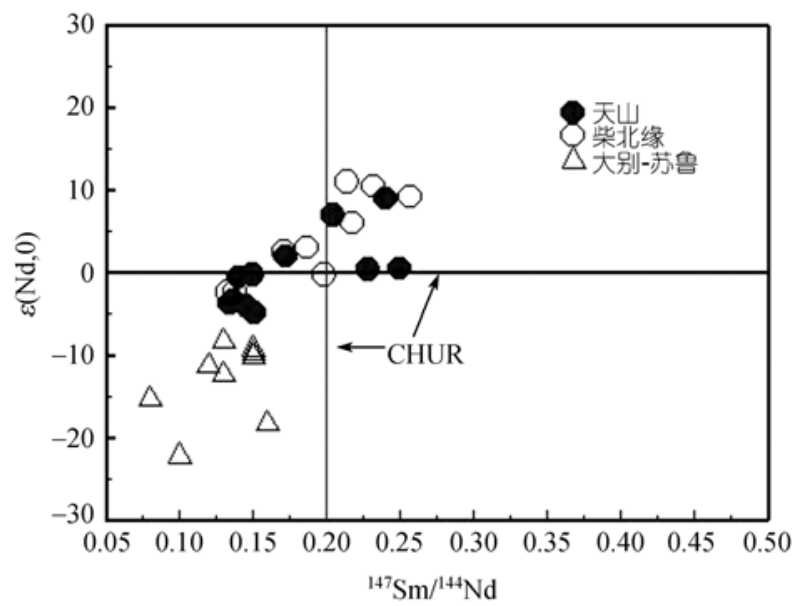

图 2 新疆西南天山和柴北缘榴辉岩的 $\varepsilon_{\mathrm{Nd}}(0)$ 与 ${ }^{147} \mathrm{Sm} /{ }^{144} \mathrm{Nd}$ 图解

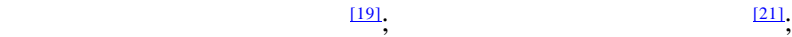
大别-苏鲁榴辉岩据Jahn等人[22]

\section{2 变质作用特征}

由洋壳岩石深俯冲形成的超高压变质榴辉岩通 常与蓝片岩相变质作用伴生, 在进变质阶段常出现 硬柱石蓝片岩相，峰期变质的温度多发生在低温榴 辉岩相范围 $\left(600^{\circ} \mathrm{C} \text { 左右 }\right)^{[24]}$. 地热梯度也都比较低, 
甚至接近 $5^{\circ} \mathrm{C} / \mathrm{km}$. 如新疆西南天山超高压变质榴辉 岩出现了从硬柱石蓝片岩相到低温榴辉岩相、再到超 高压变质的柯石英榴辉岩相阶段和退变的绿穷石蓝 片岩相阶段, 峰期的温度 $600^{\circ} \mathrm{C}$, 压力达 $2.8 \sim 3.0$ $\mathrm{GPa}{ }^{[6,7]}$, 而榴辉岩相变质泥质片(麻)岩的压力高达 $5.0 \mathrm{GPa}$, 最低的地热梯度接近 $4^{\circ} \mathrm{C} / \mathrm{km}^{[8]}$ ，属于典型 的低温榴辉岩带. 西Alps的Zermatt-saas地区超高压 变质带矿物组合中出现大量的含水矿物, 在石榴石 多硅白云母片岩中的石榴石变斑晶中发现有柯石英 和柯石英假象 ${ }^{[5]}$, 利用石榴石Gibbs微分热力学方程 计算的峰期温压条件为: $2.7 \sim 3.0 \mathrm{GPa}, 600 \sim 630^{\circ} \mathrm{C}^{[25]}$; 在变质枕状玄武岩中发现了峰期变质矿物组合 $\mathrm{Mg}-\mathrm{Ctd}+\mathrm{Tc}+\mathrm{Omp}+\mathrm{Gt}, P-T$ 视剖面计算的结果表明, 其 峰期的温压条件达到 2.5 3.0 GPa, 550 600 ${ }^{\circ} \mathrm{C}^{[14]}$, 退 变过程经历了绿帘石蓝片岩相的叠加. 目前发现的 洋壳深俯冲超高压变质带均属于典型的冷俯冲带.

\section{3 岩石组合特征}

超高压变质洋壳岩石与蛇绿岩密切伴生, 是洋 壳俯冲型造山带的主要组成特征, 也是与大陆深俯 冲超高压变质带明显不同之处. 如西南天山超高压 变质榴辉岩带与蛇绿岩带密切伴生, 在没有发现榴 辉岩之前, 一直是根据蛇绿岩带来确定其缝合带位 置. 西Alps的Zermatt-saas带中保存有大量没有变质 的层状辉长岩以及部分变质为榴辉岩的辉长岩和上 部硅质岩 [14]. 柴北缘超高压变质带中, 最近在沙柳河 剖面中已识别出了从底部的变质蛇绿岩型地幔橄榄 岩、层状辉长岩(蓝晶石榴辉岩)及其上的变质玄武岩 (细粒榴辉岩)等组成的肢解的蛇绿岩剖面 ${ }^{[13,26]}$, 表明 在柴北缘大陆深俯冲之前存在有洋壳深俯冲的过程.

\section{2 大洋型超高压变质带的研究意义}

有关洋壳深俯冲超高压变质带研究的作者曾做 过简单的介绍 ${ }^{[24,27]}$, 本次在已有的基础上进一步概 括为以下 4 个方面.

\section{1 洋壳冷俯冲超高压变质相反应系列及其地质意义}

洋壳岩石深俯冲超高压变质作用的重要特征是 峰期变质的温度较低, 接近 $600^{\circ} \mathrm{C}$, 属于低温超高压 变质作用类型 ${ }^{[24]}$, 其峰期变质的地热梯度接近 $5^{\circ} \mathrm{C} /$ $\mathrm{km}$, 属于典型的冷俯冲带. 目前根据对现今日本岛的 地球物理观测和数值模拟计算结果, Peacock和Wang ${ }^{[28]}$ 以及Kirby ${ }^{[29]}$ 等提出俯冲带可以进一步划分为冷俯冲 型(cold subduction)和热俯冲型(warm subduction): 冷
俯冲带板块俯冲速度比较快(如日本的东北部分, 太平 洋板块俯冲速度可以达到 $91 \mathrm{~mm} / \mathrm{a}$ ), 地热梯度小于 5 ${ }^{\circ} \mathrm{C} / \mathrm{km}$, 可以把大量的水流体带入到上地幔或更深的 地幔中, 产生较广泛的火山岛链和引发中-深度地震; 而热俯冲带板块俯冲速度较慢(如日本的西南部分, 菲律宾板块俯冲速度较慢达到 $45 \mathrm{~mm} / \mathrm{a}$ ), 地热梯度 在 $10^{\circ} \mathrm{C} / \mathrm{km}$ 以上, 由于地热梯度较高, 水流体不容易 被带入地幔的深度, 因而一般不发育岛弧岩浆作用. 目前发现的洋壳深俯冲超高压变质带是地质历史中 发生的最典型的冷俯冲变质带, 是最有可能的地幔 水流体等的传送带. 而这些水流体的载体矿物目前 看来主要有多硅白云母、硬柱石、叶蛇纹石等含水矿 物 ${ }^{[30]}$ 和高密度含水富镁硅酸盐相物质DHMS(Dense Hydration Maganisian Silicates): phase A, B, C, D, E, $\mathrm{Pi}$ 和 $10 \AA$ 相等 ${ }^{[31,32]}$ 以及少量名义上不含水的矿物含有 的微量水.

冷俯冲带是根据现今板块俯冲带地球物理观测 提出来的, 但在变质相及变质相反应系列方面还没 有深入的工作. 据Peacock和Wang ${ }^{[28]}$ 的热模拟计算推 测冷俯冲变质过程中普遍经历了硬柱石蓝片岩相到 硬柱石榴辉岩相的变质过程, 但没有与玄武岩熔融 曲线相交, 因而可以将地壳浅处的水流体带到地幔 深处去. 而热俯冲带经历了绿片岩相、绿穷角闪岩相 和绿穷石榴辉岩相的变质转化过程, 并且在俯冲 100 $\mathrm{km}$ 左右与玄武岩熔融曲线相交, 产生埃达克质岩浆, 因而不可能将地壳浅处的水流体带到地幔中去. Peacock和Wang ${ }^{[28]}$ 的热模拟计算工作只是理论探讨, 需要研究实例的验证, 如不同原岩体系包括玄武岩 体系(NCFMASH)和超基性岩体系(CFMASH)中出现 的变质矿物组合在洋壳俯冲超高压变质冷俯冲带中 是如何转化的? 有关这方面的深入研究有助于我们 对冷俯冲变质带形成动力学过程的认识, 建立新的 超高压变质作用类型, 从而对探讨地幔水流体等的 成因具有重要意义.

\section{2 超高压变质洋壳岩石的抬升、保存机制}

目前地球物理和深源地震研究表明洋壳深俯冲 可以达到下地幔乃至核幔边界. 但为什么洋壳超高 压变质岩石出露的如此稀少? 其中一个重要原因就 是俯冲到地幔深度经历了超高压变质的洋壳岩石很 难再折返到地表, 因此有关其抬升机制的研究对于 揭示俯冲碰撞造山带形成演化过程具有重要研究意 义. 目前有关大陆深俯冲超高压变质岩抬升折返机 
制方面已提出了由于深俯冲的洋壳与陆壳断开后, 陆壳岩石比重在上地幔深度低于周围的岩石, 因而 浮力作用可以导致其抬升 ${ }^{[33,34]}$. 近年研究进一步提 出了整体抬升模式和拆离解耦折返模式 ${ }^{[35,36]}$, 但对 于洋壳岩石就不能简单地用浮力抬升机制解释了, 因为深俯冲的洋壳岩石转变为榴辉岩后, 在上地幔 的密度比周围地幔岩石要大, 很难在地幔深度上产 生浮力作用而上升折返. 实际上在没有超高压变质岩 发现之前, 人们就开始关注洋壳岩石的抬升折返和保 存机制问题. 提出的主要模式有增生楔模式 ${ }^{[37]}$ 、双通 道(角流)模式 ${ }^{[38]}$ 、底辟上升模式 ${ }^{[39]}$ 和地幔橄榄岩蛇纹 石化浮力上升模式 ${ }^{[40]}$ 等. 但这些模式的提出主要是 依据没有经历过超高压变质的、俯冲比较浅的(40 50 $\mathrm{km})$ 蓝片岩和低温榴辉岩的研究为基础的, 并且着重 强调构造挤压作用的影响. 对于俯冲到地幔深度、经 历了超高压变质的洋壳岩石的研究比较少, 目前只 有西Alps的Zermatt-Saas带开展了这方面的研究工作, 如 Klauw 等人 ${ }^{[41]}$ 根据岩石学和变形分析提出了 Zermatt-Saas带中超高压变质榴辉岩的三阶段PT轨迹 的构造抬升模式, 强调了构造变形在抬升过程中的 重要作用, 但对于抬升的机理和动力学过程没有更 深入的工作; Hermann 等人 ${ }^{[40]}$ 通过对西 Alps 的 Penninic带中的由辉长岩变质形成的榴辉岩和蛇纹石 化地幔橄榄岩的岩石学和构造变形关系的研究, 提 出了地幔橄榄岩的蛇纹石化过程使得其比重降低, 产生的浮力作用使得伴生的榴辉岩抬升. 但是这个 模型只适用与蛇纹石化地幔橄榄岩伴生在一起的榴 辉岩, 很难解释那些没有与蛇纹岩在一起的超高压 变质的榴辉岩的折返过程. 因此, 经历了超高压变质 的洋壳岩石的抬升机制的研究, 对于目前普遍接受 的大陆深俯冲超高压变质岩石的浮力抬升机制具有 较大的挑战性, 其研究对于建立更加广泛的超高压 变质岩石的抬升保存机制问题具有重要研究意义.

\section{3 洋壳岩石深俯冲超高压变质过程中元素地球化} 学行为及物质循环

洋壳深俯冲与陆壳深俯冲最明显的区别是洋壳 俯冲过程中释放出大量的流体, 这种高温超临界流 体可以溶解一些岩石中的不相容元素, 并交代上覆 岩石圈地幔, 使其部分熔融, 产生岛弧玄武岩浆 ${ }^{[42]}$. 通常认为岛弧岩浆的起源深度在 90 150 km左右 [42 44], 这一深度恰好与洋壳深俯冲发生超高压变质 作用的极限深度相当 (西Alps的Zermatt-Saas为
$90 \mathrm{~km}$ 以上; 西天山 $150 \mathrm{~km}$ 左右). 以往对于岛弧玄武 岩浆成因研究主要是根据岛弧岩浆的岩石地球化学 特征( 亏损高场强元素Nb, Ta, Zr, Hf; 富集大离子亲 石元素Ba, Rb, Cs, Sr等), 提出了由于俯冲下去的洋 壳板块脱水作用, 使得一些易溶于水流体的大离子 亲石元素向上迁移, 降低了上覆板块岩石圈地幔部 分熔融的温度, 使得它们发生熔融形成了岛弧火山 岩, 因此岛弧火山岩具有亏损高场强元素, 而富集大 离子亲石元素的特征. 如果这种假设是正确的话, 洋 壳深俯冲发生超高压变质作用折返地表的榴辉岩和 同时形成的岛弧火山岩之间在地球化学方面就应该 存在有明显的耦合成因关系，即岛弧火山岩中富集 大离子亲石元素、亏损高场强元素, 而超高压变质的 榴辉岩中就应该亏损大离子亲石元素、富集高场强元 素. 目前的研究表明, 在俯冲达到 $90 \mathrm{~km}$ 深处的一些 大离子亲石元素(LILE)以及LREE等在小范围内发生 了迁移, 但是其变化的量比较小, 往往在原岩石中并 没有明显变化 ${ }^{[45]}$. Bebout ${ }^{[45]}$ 进一步总结出了这些元 素变化趋势与洋脊变质作用和俯冲带变质作用间的 关系鉴别图.

目前出露在地表的超高压变质洋壳岩石是经历 了由大洋玄武岩经脱水作用形成蓝片岩、榴辉岩和超 高压变质榴辉岩等一系列过程的最后产物, 因此针 对这些地质出露体开展洋壳超高压变质岩的成因地 球化学研究, 对于研究元素地球化学行为、进而探讨 岛弧火山岩的成因过程具有重要意义.

2.4 由洋壳俯冲到陆壳的俯冲、碰撞: 造山带的形 成与演化

根据现今板块构造理论, 一个典型的俯冲碰撞 造山带的形成通常是由于大洋地壳在海沟处向另一 个板块之下俯冲, 在活动大陆一侧形成岛弧岩浆-低 压高温变质带, 不断俯冲的洋壳牵引着陆壳向另一 个陆壳之下俯冲碰撞, 最后深俯冲的洋壳与所拖曳 的陆壳断开(breakoff) ${ }^{[33,46]}$, 俯冲下去的陆壳抬升、隆 起与活动大陆边缘带岩石混杂组成了造山带. 在这 样的一个地球动力学过程中, 由洋壳俯冲到陆壳俯 冲、碰撞是两个重要阶段. 目前已在世界范围内的一 些典型的俯冲碰撞造山带中建立起了由洋壳俯冲到 陆壳碰撞的演化机制. 其中研究程度最高的是经历 了超高压变质过程、现今还在进行的由新Tethys洋的 消失形成的阿尔卑斯造山带和喜马拉雅造山带. 
阿尔卑斯造山带经过 200 多年的研究，目前已成为造山 带研究的最经典地区. 它的形成通常认为是欧洲板块 向Adriatic(非洲)板块下俯冲-碰撞形成的 ${ }^{[47]}$. 目前地质 学家们较一致的认为西阿尔卑斯造山带经历了以下几 个重要阶段: 165 Ma时 Alps中最大的洋 PiemontLiguian 洋开始形成, 大约在 $100 \mathrm{Ma}$ 时 PiemontLiguian洋开始俯冲, 65 Ma时Piemont-Liguian洋中的 Sesia洋盆关闭 ${ }^{[48]}$; 44 Ma时Piemont-Liguian洋俯冲结 束 ${ }^{[48]}$, 在Zermatt-saas带中形成了高压-超高压变质的 榴辉岩; 33 35 Ma时残余的Valais洋继续俯冲, 带动 着陆壳进一步俯冲碰撞形成了 Dora Maira陆壳深俯 冲超高压变质带 449,50$]$. 相比之下，尽管喜马拉雅造山 带没有阿尔卑斯造山带的研究程度高, 但造山带形 成演化的几个重要阶段的事实也基本清楚了, 即中 生代侏罗纪晚期Tetys洋开始俯冲, 晚白严世古Tethys 消失形成了班公缝合带, 晚白严世晚期至第三纪早 期, 新Tetys洋开始俯冲消失, 印度板块与亚洲板块 碰撞 ${ }^{[51]}$. 虽然最后缝合的时限有争议, 但最近的含柯 石英榴辉岩给出的变质时限为 $46 \sim 55 \mathrm{Ma}^{[52]}$, 这与西 阿尔卑斯的Zermatt-saas带中洋壳俯冲变质的时代(44 $\mathrm{Ma)}$ 基本一致, 但比Dora Maira陆壳深俯冲碰撞的时 代要早 $10 \mathrm{Ma}$ 左右.

阿尔卑斯和喜马拉雅最年轻的造山带的实例研 究显示: 一个俯冲碰撞造山带的形成经历了由洋壳 俯冲到陆壳俯冲、碰撞的过程, 持续的时间都比较长, 如西阿尔卑斯约为 70 80 $\mathrm{Ma}^{[51]}$. 洋壳俯冲作为陆壳 俯冲的先导条件, 是导致一个陆壳能够俯冲到另一 个陆壳之下的主要原因之一。没有洋壳俯冲就可能 没有陆壳的俯冲, 没有洋壳与陆壳的断离, 也就可能 没有陆壳的抬升和折返, 这些动力学的联系是建立 俯冲碰撞造山带地质演化的基础, 因此洋壳深俯冲 超高压变质作用研究无论对于研究大陆深俯冲作用 发生的机理, 还是探讨深俯冲的大陆地壳岩石抬升 和折返的动力学机制都具有重要意义.

\section{3 中国西部超高压变质带研究现状及问题}

中国西部西南天山和柴北缘超高压变质带是继 东部大别-苏鲁超高压变质带之后, 新发现的 2 条超 高压变质带, 它们与大别-苏鲁超高压变质带最显著 的区别是它们的原岩都具有洋壳岩石组合特征, 如 图 2 所示.

\section{1 西南天山超高压变质带}

我们在西天山超高压变质带中首次报道了榴辉 岩中柯石英假象、残留的变质菱镁矿 ${ }^{[6,7]}$ 等超高压变 质证据, 曾引起了人们的关注 ${ }^{[17,53]}$, 之后我们又相继 发现了变质碳酸盐矿物间的反应关系 ${ }^{[8]}$ 和绿辉石中 柯石英出溶条纹 ${ }^{[9]}$ 等超高压变质矿物学证据, 最近又 发现了保存完好的柯石英包体 ${ }^{[23]}$ ，进一步证实了西 南天山榴辉岩经历了超高压变质作用. 新疆西南天 山榴辉岩-蓝片岩带与蛇纹岩化的超基性岩伴生. 主 要出露在西南天山的西部昭苏县境内(图 3), 主要由 榴辉岩、蓝片岩、多硅白云母片岩和绿片岩等所组成. 其中榴辉岩和蓝片岩呈透镜状、团块状被包裹在大面 积出露的石榴白云母片岩中. 其北界与由含堇青石 榴矽线石片麻岩和二辉麻粒岩所组成的低压高温变 质带以韧性剪切带为界 ${ }^{[54]}$; 其南缘也是以韧性剪切 带为界与互层状的大理岩和绿泥石白云母片岩相邻. 该变质带通常被认为是南天山古洋盆在古生代闭合 过程中由塔里木板块向伊犁-中天山板块俯冲发生高 压低温变质作用形成 $[18,55]$.

根据野外地质产状特征, 西南天山出露的榴辉 岩可以分为 3 类: 即在蓝片岩中呈透镜体产出的块状 榴辉岩、保存有玄武岩岩枕的枕状榴辉岩和夹杂在大 理岩中的条带状榴辉岩 ${ }^{[18,55,56]}$, 最近的研究又发现了 在石榴石多硅白云母片岩中的呈包体状榴辉岩类型 [57]. 详细的岩石学研究表明它们都经历过超高压变质 作用, 其变质作用演化经历了 3 个阶段：峰期榴辉岩 阶段 $\left(560 \sim 600^{\circ} \mathrm{C}, 4.95 \sim 5.07 \mathrm{GPa}\right)$ 、主期榴辉岩阶段 (598 496 $\left.{ }^{\circ} \mathrm{C}, 2.58 \sim 2.67 \mathrm{GPa}\right)$ 和退变绿帘石蓝片岩相阶 段 ${ }^{[9,56]}$. 地球化学研究显示其原岩相当于源于富集地 幔的 $\left(\varepsilon_{\mathrm{Nd}}(t)=-1.4 \sim-0.4, t=225 \mathrm{Ma}\right.$, 艾永亮等人 ${ }^{[19]}$, 下同)具有OIB特点的变碱性玄武岩、源于亏损地幔 的 $\left[\varepsilon_{\mathrm{Nd}}(t)=6.7 \sim 7.4\right]$ 具有 N-MORB特点的洋中脊玄武岩 和源于较富集地幔的 $\left(\varepsilon_{\mathrm{Nd}}(t)=-2.5 \sim 3.2\right)$ 具有 E-MORB 特点的洋中脊玄武岩, 它们形成于海山环境下的洋壳 [19]. 榴辉岩中锆石SHRIMP最新定年结果榴辉岩的原 岩形成于石炭纪(>310 Ma)之前, 洋壳开始俯冲发生在 二叠纪末(280 290 Ma), 高压-超高压变质发生在三叠 纪(220 230 Ma ${ }^{[16]}$. 结合在其北侧发现的低压麻粒岩 带 ${ }^{[54]}$, 提出了新疆西南天山超高压变质带双变质带构 造演化模式 $\frac{16,56]}{}$. 同时在变质超基性岩中发现了由榴 辉岩转变形成的异剥钙榴岩, 表明西南天山超高压变 质俯冲带的流体活动非常强烈 ${ }^{[13]}$. 


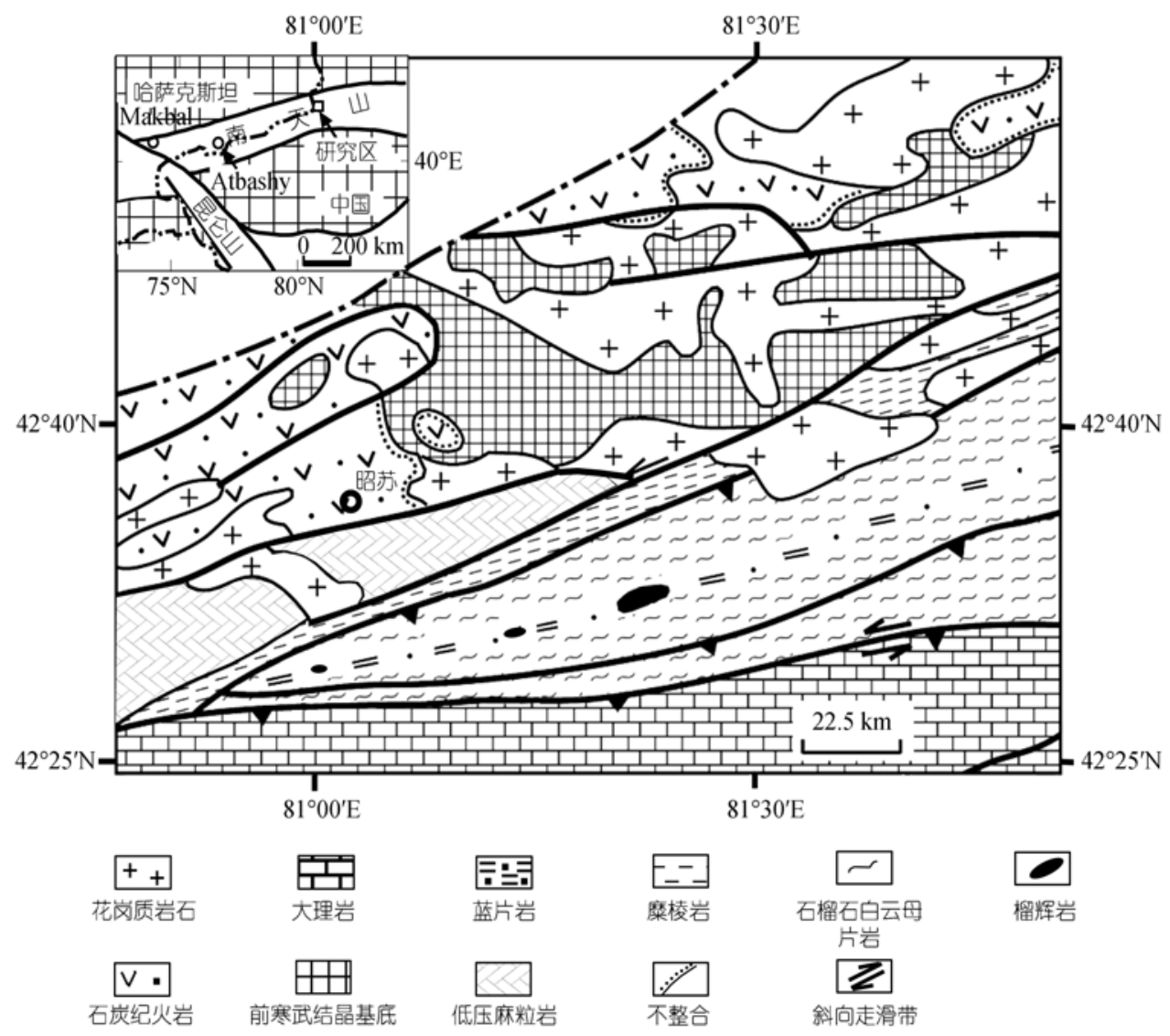

图 3 新疆西南天山超高压-高压变质带地质图 1 16]

目前研究存在的问题也较多:

(i ) 洋壳岩石抬升、折返机制问题. 西南天山具 有典型的洋壳深俯冲超高压变质带特征, 为我们开 展有关超高压变质洋壳岩石的抬升、折返这一前沿课 题研究提供了得天独厚的地域优势. 但需要对超高 压变质地体开展详细的岩石学、同位素年代学、地球 化学和构造地质学研究工作, 包括详细的基于热力 学相平衡计算的岩石 PTt 轨迹的确定、超高压变质峰 期时代的确定以及变质变形关系等, 从而在探讨超 高压变质岩石抬升、折返机制方面能有所贡献.

(ii ) 西南天山造山带俯冲碰撞造山的时限问题. 目前有关西南天山造山带俯冲碰撞造山的时代有两 种不同的争论观点. 一种是利用高压变质岩中白云 母、蓝闪石的 $\mathrm{Ar} / \mathrm{Ar}$ 年龄和 $\mathrm{Sm} / \mathrm{Nd}, \mathrm{Rb} / \mathrm{Sr}$ 内部等时线方 法获得的 400 300 Ma年龄值, 提出的早古生代开始 俯冲, 晚古生代碰撞造山观点 ${ }^{[58,59]}$; 另一种则根据锆 石SHRIMP定年方法获得的 300 200 Ma年龄值, 提 出的二叠纪开始俯冲, 三叠纪碰撞 $[16,56,60]$. 这两种观
点都各有其支持证据, 有必要开展深入的地质年代 学研究工作.

(iii) 西南天山作为较少保留的洋壳深俯冲到地 幔深度而折返的地区, 是研究俯冲带变质元素地球 化学行为的理想场所. 特有的榴辉岩相的绿辉石脉 [58]和目前发现的俯冲带中由榴辉岩转变形成的异剥 钙榴岩 [61]都表明西南天山俯冲变质带发育有广泛的 流体作用. 特别是有关超高压变质的榴辉岩的元素 地球化学行为的研究对于深入探讨俯冲带中元素的 活动性具有重要意义.

\section{2 柴北缘超高压变质带}

柴北缘都兰地区的石榴石多硅白云母片麻岩中 首先发现了柯石英包体 ${ }^{[20,62]}$, 之后又相继在榴辉岩 中发现了柯石英假象/绿辉石中石英的出溶 ${ }^{[20]}$, 在石 榴石二辉橄榄岩中发现了金刚石包体 ${ }^{[63]}$, 并在南阿 尔金地区也发现了一系列超高压变质的特征矿物和 结构 ${ }^{[64 ~ 67]}$ (图 4), 进而确定出一条近东西向长达上千 公里的柴北缘超高压变质带. 它主要由柴北缘地区 


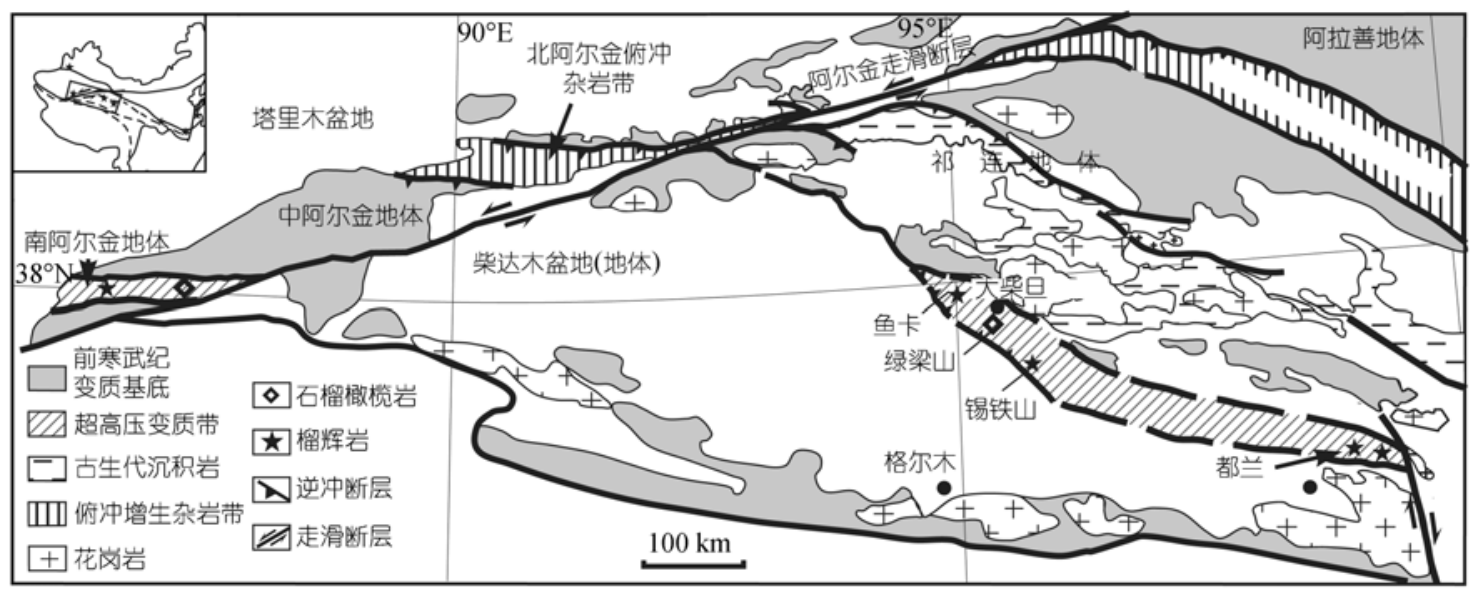

图 4 柴北缘超高压变质带分布地质图 ${ }^{[26]}$

的都兰、锡铁山、绿梁山和鱼卡河和南阿尔金等地组 成. 除绿梁山地区出露的为石榴石二辉橄榄岩, 没有 榴辉岩出露外, 其他地区都是以大面积出露的片麻 岩中夹杂着各种榴辉岩透镜体为特征(详见文献[68] 及其参考文献), 与大别-苏鲁超高压变质带相似, 都属 于以中温超高压变质为主, 和少量的石榴石二辉橄 榄岩出露为特征的超高压变质地区.

但与大别-苏鲁超高压变质带中榴辉岩明显不同 的是, 柴北缘榴辉岩的原岩具有洋壳玄武岩特征, 如 都兰北带的榴辉岩具有大洋玄武岩地球化学特征 ${ }^{[20]}$, 鱼卡河和锡铁山榴辉岩也都具有洋壳玄武岩特征 [21]. 变质作用研究表明他们具有两类不同的PT轨迹, 都兰 北带榴辉岩和鱼卡河榴辉岩的PT轨迹相似都具有近 等温降压特征 ${ }^{[69,70]}$, 而都兰南带和锡铁山地区其退变 轨迹则出现降压升温的热驰豫过程 ${ }^{[20,69]}$. 是否柴北缘 超高压变质带中榴辉岩都是属于洋壳深俯冲变质的产 物还有待做进一步研究工作. 我们最近的工作在沙柳 河剖面中识别出了具有保存较完整的“肢解”的榴辉岩 相变质蛇绿岩组合, 并在层状辉长岩变质的榴辉岩中 发现了柯石英 ${ }^{[71]}$, 表明柴北缘超高压变质带中至少存 在有洋壳深俯冲超高压变质的榴辉岩.

目前争论比较大的问题:

(i ) 柴北缘 4 个超高压变质地区的峰期变质时 代问题. 目前这 4 个地区的峰期变质时代有明显差异, 如鱼卡河(488 Ma, Zhang等人 ${ }^{[69]}$; 431 436 Ma陈丹玲 等人 ${ }^{[69]}$ )、绿梁山(石榴石二辉橄榄岩 420 423 Ma, Song 等人 ${ }^{[63]}$; 高压麻粒岩 $447 \mathrm{Ma}$, 张建新等人 ${ }^{[72]}$ )、锡铁 山(480 486 Ma, Zhang等人 $\left.{ }^{[69]}\right)$ 和都兰(457 423 Ma,
Song等人 ${ }^{[3]}$; 449 442 Ma, Mattinson等人 ${ }^{[73]}$ ), 这些测 定的年龄值的不同，是由于方法不同还是由于造山 带演化的穿时性所致? 另外即使在同一地区得到相 同的时代, 解释上也有差异, 因此峰期变质同位素年 代学问题仍将是柴北缘超高压变质带时空演化的关 键问题之一.

(ii ) 自从在都兰北带榴辉岩的围岩片麻岩中发 现柯石英包体, 通常认为柴北缘超高压变质带属于 大陆型超高压变质带. 但是, 有关榴辉岩原岩地球化 学的一系列研究表明, 榴辉岩的原岩具有大洋玄武 岩的特征. 对于这种大面积陆壳岩石中出现原岩具 有洋壳性质的榴辉岩的成因解释上目前有两种完全 不同的观点. 一种认为“冷”就位于大陆地壳之中的 残留蛇绿岩片, 与陆壳岩石一起深俯冲经历了超高 压变质 21,74$]$. 另一种则认为是早期洋壳俯冲带动着 陆壳进一步俯冲发生超高压变质, 经历了超高压变 质的陆壳岩石上升、折返过程中裹带着一些洋壳断离 后残留的洋壳榴辉岩抬升出露地表, 进而提出了柴 北缘超高压变质带由洋壳俯冲到陆壳俯冲碰撞的演 化模式 ${ }^{[26,63]}$. 近年来, 我们在柴北缘沙柳河剖面识别 出了由层状辉长岩变质形成的蓝晶石榴辉岩, 这是 目前柴北缘超高压带中唯一发现的由辉长岩转化形 成的榴辉岩 ${ }^{[13]}$. 并且这种条带状含蓝晶石榴辉岩与 底部的变质超基性岩和上部的细粒榴辉岩以及其上 部的大理岩中薄层状榴辉岩, 构成了变质的蛇绿岩 剖面, 代表柴北缘大陆型超高压变质带中残留的洋 壳. SHRIMP定年结果表明, 蓝晶石榴辉岩的原岩年 龄为 $(516 \pm 8) \mathrm{Ma}$, 而变质年龄为 $(445 \pm 7) \mathrm{Ma}$, 进一步 
证明了柴北缘由洋壳俯冲到陆壳俯冲碰撞的演化过 程 ${ }^{[23]}$. 如果上述地质事实得到进一步证实, 柴北缘超 高压变质带可能是目前较少保留有陆壳深俯冲和洋 壳俯冲在同一地区出露, 对于比较洋壳俯冲与陆壳 俯冲和折返差异、探讨由洋壳俯冲到陆壳俯冲碰撞造 山过程具有重要意义.

(iii) 柴北缘超高压变质带与北祁连高压低温变 质带的成因联系? 柴北缘超高压变质带北侧出现了 北祁连低温榴辉岩-蓝片岩带, 其峰期变质时代为 463 468 $\mathrm{Ma}^{[26]}$, 与柴北缘高压变质时代相近, 但比 柴北缘超高压变质时代(423 Ma, Song等人 ${ }^{[3]}$ )略早 40 50 Ma. 目前有关这两个高压-超高压变质带的关 系也有不同的看法, 一种认为代表两次不同的俯冲 事件 [62]; 而另一种观点则认为是一次俯冲的不同过 程 ${ }^{3]}$. 有关北祁连高压变质带与柴北缘超高压变质带
之间的成因联系有待进一步深入的工作.

总之, 大洋型超高压变质带的基本特征是以具 有典型的洋壳组合的原岩建造为特征, 其变质作用 峰期温度较低属于低温榴辉岩相范围, 在递进和退 变过程中出现蓝片岩相变质过程, 具有低的、冷俯冲 带的地热梯度, 并且在岩石组合方面常常与蛇绿岩 带伴生. 大洋型超高压变质带是近年来超高压变质 作用研究取得的重要进展之一, 对进一步发展和完 善板块构造理论、探讨俯冲带物质循环和演化、揭示 俯冲碰撞造山带的地球动力学过程都具有重要研究 意义. 中国西部西南天山和柴北缘两条新发现的超 高压变质带, 都具有大洋型超高压变质带地质特征, 为开展大洋型超高压变质带研究提供了难得的地域 优势, 进一步开展深入研究可望在这一领域获得重 要突破性成果.

致谢感谢郑永飞教授的邀稿, 两位评审人的认真评阅.

\section{参考文献}

6 Zhang L F, David J Ellis, Jiang W B. Ultrahigh pressure metamorphism in western Tianshan, China, part I : Evidences from the inclusion of coesite pseudomorphs in garnet and quartz exsolution lamellae in omphacite in eclogites. Am Min, 2002, 87: 853-860

7 Zhang L F, David J Ellis, Samantha Williams, et al. Ultrahigh pressure metamorphism in western Tianshan, China, part II : Evidence from magnesite in eclogite. Am Min, 2002, 87: 861-866

8 Zhang L F, David J Ellis, Richard J A, et al. Ultradeep subduction of carbonates to the mantle: Evidence from the carbonate reaction of magnesite + calcite (aragonite) $=$ dolomite in metapelites from western Tianshan, China. J Met Geol, 2003, 21: 523-529 [DOD]

9 Zhang L F, Song S G, Ai Y L, et al. Relict coesite exsolution in omphacite from western Tianshan eclogites, China. Am Mineral, 2005, 89: $180-186$

10 Li X P, Rahn M, Bucher K. Serpentinites of the Zermatt-Saas ophiolite complex and their texture evolution. J Met Geol, 2004, 22: 159$177 \underline{\text { DOI] }}$

11 李旭平, 张立飞, 艾永亮. 新疆西天山长阿吾子蛇绿混杂岩中与榴辉岩伴生的异剥钙榴岩. 自然科学进展, 2003, 13: 103一 109

12 Li X P, Zhang L F, Wei C J, et al. Petrology of rodingites derived from eclogites in the western Tianshan, China. J Met Geol, 2007, 25: 363 - 382 [DOI]

13 张贵宾, 宋述光, 张立飞, 等. 柴北缘超高压变质带沙柳河蛇绿岩型地幔橄榄岩的发现及其意义. 岩石学报, 2005, 21(4): 1049-1058

14 Bucher K, Fazis Y, Capitani C, et al. Blueschists, eclogites, and decompression assemblages of the Zermatt-Saas ophiolite: High-pressure metamorphism of subducted Tethys lithosphere. Am Min, 2005, 90: 821-835[DOI]

杨建军，朱红、邓晋福，等。柴达木北缘石榴石橄榄岩的发现及其意义. 岩石矿物学杂志, 1994, 13(2): 97-104 
Zhang L F, Ai Y, Song S, et al. Triassic collision of Western Tianshan orogenic belt, China: Evidences from SHRIMP U-Pb dating of zircon from eclogitic rocks. Lithos, 2007, 96: 266-280[DOI]

张立飞, 吕增, 李旭平, 等. 西阿尔卑斯 Zermatt-saas 洋壳深俯冲超高压变质带及其与中国新疆西南天山超高压变质带的比 较. 高校地质学报, 2007, 3: 498-506

张立飞, 高俊, 艾科拜尔, 等. 新疆西天山低温榴辉岩相变质作用研究. 中国科学 D 辑: 地球科学, 2000, 30(4): 345一-354

艾永亮, 张立飞, 李旭平, 等. 新疆西南天山昭苏一带超高压变质榴辉岩、蓝片岩地球化学特征及其大地构造意义. 自然科 学进展, 2005, 11: 1346-1356

Song S, Yang J, Xu Z, et al. Metamorphic evolution of the coesite-bearing ultrahigh-pressure terrane in the north Qaidam, northern Tibet, NW China. J Met Geol, 2003, 21: 631-644[DOD]

21 杨经绥, 张建新, 孟繁聪, 等. 中国西部柴北缘一一阿尔金的超高压变质榴辉岩及其原岩性质探讨. 地学前缘, 2003, 10: 291一 313

Jahn B M, Rumble D, Liou J G. Geochemistry and isotope tracer study of UHP metamorphic rocks. In: Carswell D A, Compagnoni R, eds. Ultrahigh Pressure Metamorphism. Budapest: Eotvos University Press, 2003. 365-414

LÜ Z, Zhang L F, Du J X, et al. Coesite inclusions in garnet from eclogitic rocks in western Tianshan, NW China, ABSTRCT of International Eclogite Field Symposium. England, 2007. 137-138

张立飞. 极端条件下的变质作用: 变质地质学研究的前沿. 地学前缘, 2007, 14: 33-42

\section{matt-Saas Zone, western Alps. Lithos, 1998, 42: 147-189 [DOI]}

Zhang G B, Song S G, Zhang L F, et al. The subducted oceanic crust within continental-type UHP metamorphic belt in the North Qaidam, NW China: Evidence from petrology. Geochemistry and geochronology. Lithos, 2007, doi: 10.1016/j.lithos. 2007.12.001 [DOI]

张立飞. 洋壳深俯冲超高压变质作用研究及其地质意义. 地质通报, 2007, 26: 1079-1085

east Japan. Science, 1999, 286: 937-939 DOI]

Kirby S. Taking the temperature of slabs. Nature, 2000, 403: 31-34[DO]

Schreyer W. Ultradeep metamorphic rocks, the retrospective viewpoint. J Geophys Res, 1995, 100: 8353 - 8366[DOI]

Wunder B. Equilibrium experiments in the system $\mathrm{MgO}-\mathrm{SiO}_{2}-\mathrm{H}_{2} \mathrm{O}(\mathrm{MSH})$ : Stability fields of clinohumite-OH, chondrodite-OH and phase A. Contrib Mineral Petrol, 1998, 132: 111-120 [DOI]

Davies J H, von Blanckenburg F. Slab breakoff, a model of lithospher detachment and its test in the magmatism and deformation of collisional orogens. Earth Planet Sci Lett, 1995, 129: 85-102[DO]

Ernst W G. Subduction, ultrahigh-pressure metamorphism, and regurgitation of buoyant crustal slices- implications for arcs and continental growth. Phys Earth Planet Int, 2001, 127: 253-275[DOI]

李曙光, 李秋立, 侯振辉, 等. 大别山超高压变质岩的冷却史及折返机制. 岩石学报, 2005, 21(4): 1117-1124

Liu Y C, Li S G, Xu S T. Zircon SHRIMP U-Pb dating for gneiss in northern Dabie high T/P metamorphic zone, central China: Implication for decoupling within subducted continental crust. Lithos, 2007, 96: 170-185[DOI]

Platt J P. Dynamics of orogenic wedges and the uplift of high pressure metamorphic rocks. Bull Geol Soc Am, 1986, 97: 1037-1053[DOI]

Cloos M. Blueschist in the Franciscan Complex of California: petrotectonic constraints on uplift mechanism. Geol Soc Am Mem, 1986, 164: 77-94

Hall P S, Kincaid C. Diapiric flow at subduction zones: A recipe for rapid transport. Science, 2001, 292: 2472 - 2475[DOI]

Hermann J, Muntener O, Scambelluri M. The importance of serpentinite mylonites for subduction and exhumation of oceanic crust. Tectonophysics, 2000, 327: 225-238 [DOI]

41 Klauw G, Reinecke T. Exhumation of ultrahigh-pressure metamorphic oceanic crust from Lago di Cignana, Piemontese zone, western Alps: The structural record in metabasites. Lithos, 1997, 41: 79-102 [DOI]

Gill J B. Orogenic Andesites and Plate Tectonics. Berlin: Speringer, 1981. 390

Tatsumi Y. Formation of the volcanic front in subduction zones. Geophys Res Lett, 1986, 13: 717-720 $\underline{\text { DOD }}$

Forneris T, Holloway J. Phase equilibria in subductiong basaltic crust: Implications for $\mathrm{H}_{2} \mathrm{O}$ release from the slab. Earth Planet Sci Lett, 2003, 214: 187-201 [DOI]

Bebout G. Metamorphic chemical geodynamics of subduction zone. Earth Planet Sci Lett, 2007, 260: 373 - 393 [DOI] 
the geodynamic evolution of the Central and Western Alps. Contrib Min Petrol, 1998, 132(3): 269-287[DOI]

Rubatto D, Hermann J. Exhumation as fast as subduction? Geology, 2001, 29: 3-6 [DOI]

Rosenbaum G, Lister G. The Western Alps from the Jurassic to Oligocene: Spatio-temporal constraints and evolutionary reconstructions. Earth Sci Rev, 2005, 69: 281-306[DOI]

O’Brien P. Subduction followed by collision: Alpine and Himalayan examples. Phys Earth Planet Int, 2001, 127: 277-291 [DOI]

Kaneko Y, Katayama I, Yamamoto H, et al. Timing of Himalayan ultrahigh-pressure metamorphism: Sinking rate and subduction angle of the Indian continental crust beneath Asia. J Met Geol, 2003, 21: 589-599 [DOD]

Klemd R. Ultrahigh-pressure metamorphism in eclogites from the western Tianshan High-pressure belt (Xinjiang, western China)Comment. Am Miner, 2003, 88: 1153-1156

李强, 张立飞. 西南天山木扎尔特一带低压麻粒岩相变质作用 PT 轨迹及其地质意义. 岩石学报, 2004, 20: 583-594

Gao J, Klemd R, Zhang L, et al. PT path of high-pressure metamorphic rocks and its tectonic implication in western Tianshan, northwest China. J Met Geol, 1999, 17: 621-636 [DOI]

张立飞，艾永亮，李强，等。新疆西南天山超高压变质带的形成与演化. 岩石学报, 2005, 21: 1029-1038

吕增, 张立飞, 曲军锋, 等. 新疆西南天山哈布腾苏一带榴辉岩的岩石学及变质作用 PT 轨迹. 岩石学报, 2007, 23: 1617一 1626

Gao J, Klemd R. Primary fluids entrapped at blueschist to eclogite transition: Evidence from the Tianshan meta-subduction complex in northwestern China. Contrib Miner Petrol, 2001, 142: 1-14

高俊, 张立飞, 刘圣伟。西天山蓝片岩榴辉岩形成和抬升的 ${ }^{40} \mathrm{Ar}-{ }^{39} \mathrm{Ar}$ 年龄记录. 科学通报, 2000, 45(1): 89-94

肖文交, 韩春明, 袁超, 等. 新疆北部石炭纪一二叠纪独特德构造-成矿作用: 对古亚洲洋构造域南部大地构造演化的制约. 岩石学报, 2006, 22: 1062-1076

Li X P, Zhang L F, Wei C J, et al. Petrology of rodingites derived from eclogites in the western Tianshan, China. J Met Geol, 2007, 25: $363-382$ [DOI]

Yang J, Xu Z, Zhang J, et al. Early Palaeozoic North Qaidam UHP metamorphic belt on the north-eastern. Tibetan plateau and a paired subduction model. Terra Nova, 2002, 14(5): 397-404표

Song S, Zhang L, Niu Y, et al. Geochronology of diamond-bearing zircons from garnet peridotite in the North Qaidam UHPM belt, Northern Tibetan Plateau: A record of complex histories from oceanic lithosphere subduction to continental collision. Earth Planet Sci Lett, 2005, 234: 99-118[DOI]

刘良, 孙勇, 罗金海, 等。阿尔金英格利萨依花岗质片麻岩超高压变质. 中国科学 D 辑: 地球科学, 2003, 33(12): 1184一-1192

刘良, 陈丹玲, 张安达, 等. 阿尔金超高压 $(>7 \mathrm{GPa})$ 片麻状(含)钾长石榴辉石岩-石榴子石出溶单斜辉石的证据. 中国科学 $\mathrm{D}$ 辑: 地球科学, 2005, 35(2): 105-114

张建新, 杨经绥, 许志琴. 阿尔金榴辉岩中超高压变质作用证据. 科学通报, 2002, 47(3): 231-234

Liu L, Zhang J, Green II H, et al. Evidence of former stishovite in metamorphosed sediments, implying subduction to $>350 \mathrm{~km}$. Earth Planet Sci Lett, 2007, 263: 180-191

张建新, 孟繁聪, Mattinson C G. 南阿尔金-柴北缘 HP/UHP 变质带研究进展、问题及挑战. 高校地质学报, 2007, 3: 526一 545 Zhang J X, Yang J S, Mattinson C G, et al. Two contrasting eclogite cooling histories, North Qaidam HP/UHP terrane, western China: Petrological and isotopic constraints. Lithos, 2005, 84: 51-76 [DOI]

陈丹玲, 孙勇, 刘良. 柴北缘鱼卡河榴辉岩的变质演化: 石榴石成分环带及矿物反应结构的证据. 岩石学报, 2005, 21: 10391048

张贵宾. 柴北缘超高压变质带沙柳河地区榴辉岩及橄榄岩岩石学研究及其大地构造意义. 博士学位论文. 北京: 北京大学, 2007. $1-97$

2 张建新, 孟智聪, 于胜尧, 等. 柴北缘绿梁山高压基性麻粒岩的变质演化历史: 岩石学及锆石 SHRIMP 年代学证据. 地学前 缘, 2007, 14: 85-97

3 Mattinson C G, Wooden J L, Liou J G, et al. Age and duration of eclogite-facies metamorphism, North Qaidam HP/UHP terrane, Western China. Am J Sci, 2006, 306: 683-711 [DOI]

74 陈丹玲, 孙勇, 刘良. 柴北缘鱼卡河榴辉岩围岩的变质时代及其地质意义. 地学前缘, 2007, 14: 108一116 